\title{
ResearchArticle
}

\section{Effect of organic nutrients and bioregulators on growth and yield of cauliflower (Brassica oleraceae L.)}

\author{
S. SRIMATHI
}

\begin{abstract}
SUMMARY
Vegetable production with organic farming has been practiced by many farmers in India. However, one of the problems in practicing organic farming is that the yield produced will be lower in the early stages compared to chemical farming. In this study, cauliflower vegetable was grown with organic fertilization in comparison with chemical fertilization, to see what accounts the yield limitation and how different in growth of the vegetable between organic and chemical fertilizations. Field experiments were conducted to study the influence of different organic manures and bioregulators on the growth and yield of cauliflower. The experiments were conducted in a Randomized Block Design replicated thrice with nine treatments involving different organic manures and bioregulators along with inorganic fertilizers as control. Efficacy of organic nutrition revealed that organic mode of nutrient through various combinations of bioregulators was found to be superior over chemical fertilizers, in terms of increased plant height, number of leaves and average yield

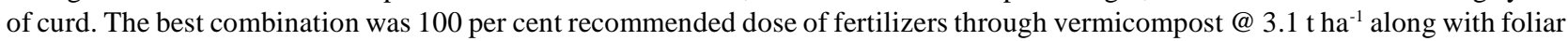
spray of humic acid $(0.1 \%)$.
\end{abstract}

Key Words : Bioregulators, Cauliflower, Farm yard manure, Organic nutrients, Vermicompost

How to cite this article : Srimathi, S. (2015). Effect of organic nutrients and bioregulators on growth and yield of cauliflower (Brassica oleraceae L.). Internat. J. Plant Sci., 10 (1): 53-56.

Article chronicle : Received : 23.08.2014; Revised : 22.11.2014; Accepted : 05.12.2014 